\title{
Adenovirus-mediated stromal cell-derived factor-1 alpha gene transfer improves cardiac structure and function after experimental myocardial infarction through angiogenic and antifibrotic actions
}

\author{
Junming Tang $\cdot$ Jianing Wang $\cdot$ Hongxian Song • \\ Yongzhang Huang $\cdot$ Jianye Yang $\cdot$ Xia Kong $\cdot$ \\ Linyun Guo $\cdot$ Fei Zheng $\cdot$ Lei Zhang
}

Received: 9 April 2009/ Accepted: 21 July 2009/Published online: 4 August 2009

(C) The Author(s) 2009. This article is published with open access at Springerlink.com

\begin{abstract}
Stromal cell-derived factor $1 \alpha$ (SDF-1) is not only a major chemotactic factor, but also an inducer of angiogenesis. The effects of SDF- $1 \alpha$ on the left ventricular remodeling in a rat myocardial infarction (MI) model were analyzed. Myocardial infarction was induced by ligation of the left coronary artery in rats. $0.5 \times 10^{10} \mathrm{pfu} / \mathrm{ml} \mathrm{AdV}$ SDF-1 or $0.5 \times 10^{10} \mathrm{pfu} / \mathrm{ml}$ Adv-LacZ were immediately injected into the infarcted myocardium, $120 \mu \mathrm{l}$ cell-free PBS were injected into the infarcted region or the myocardial wall in control, and sham group, respectively. We found that AdV-SDF-1 group had higher LVSP and $\pm \mathrm{dP} /$ $\mathrm{dt}_{\max }$, lower LVEDP compared to control or Adv-LacZ group. The number of ${\mathrm{c}-\mathrm{Kit}^{+}}^{+}$stem cells, and gene expression of SDF-1, VEGF and bFGF were obviously increased, which was associated with reduced infarct size,
\end{abstract}

Electronic supplementary material The online version of this article (doi:10.1007/s11033-009-9642-z) contains supplementary material, which is available to authorized users.

J. Tang $(\bowtie) \cdot$ J. Wang $(\bowtie) \cdot$ H. Song $\cdot$ Y. Huang $\cdot$ J. Yang

X. Kong $\cdot$ L. Guo $\cdot$ F. Zheng $\cdot$ L. Zhang

Institute of Clinical Medicine, Renmin Hospital,

Yunyang Medical College, 442000 Shiyan, Hubei,

People's Republic of China

e-mail: tangjm416@163.com

J. Wang

e-mail: rywjn@vip.163.com

J. Tang

Department of Physiology, Yun Yang Medical College,

442000 Shiyan, Hubei, People's Republic of China

J. Tang $\cdot$ J. Wang $\cdot$ H. Song $\cdot$ Y. Huang $\cdot$ J. Yang $\cdot$ X. Kong

L. Guo $\cdot$ F. Zheng $\cdot$ L. Zhang

Key Lab of Human Embryonic Stem Cell of Hubei Province, Shiyan, Hubei, People's Republic of China thicker left ventricle wall, greater vascular density and cardiocytes density in infarcted hearts of AdV-SDF-1 group. Furthermore, the expression of collagen type I and type III mRNA, and collagen accumulation in the infarcted area was lower, which was associated with decreased TGF$\beta 1$, TIMP-1 and TIMP-2 expression in AdV-SDF-1 group. Conclusion: SDF- $1 \alpha$ could improve cardiac structure and function after Myocardial infarction through angiogenic and anti-fibrotic actions.

Keywords Myocardial infarction $\cdot$ SDF- $1 \alpha \cdot$ Stem cell . Angiogenesis · Remodeling · TIMP

\section{Introduction}

The transplantation of multiple stem cell types at the time of myocardial infarction has been shown to improve left ventricular perfusion and/or function in preclinical and clinical studies. Cardiac stem cell (CSC) is pluripotent, adult stem cells and mostly resides within the bone marrow or heart. In contrast to other stem cells, c- $\mathrm{Kit}^{+}$or $\mathrm{Sca}^{+}$ Cardiac stem cells can differentiate not only into cardiomyocytes, but also into vascular endothelial cells [1]. In vivo, cardiac stem cells directly injected into an infarcted heart have been shown to induce myocardial regeneration and improve cardiac function. More importantly, when given intravenously after infarction, these cells targeted injured myocardium and differentiated into cardiomyocytes $[2,3]$. These observations prompted a search for chemotactic factors that facilitate this "homing" process. If the effects of translocated stem cells prove important in improving cardiac function, the ability to harness or augment these effects may be possible through gene transfer strategies. 
It is interesting that the cytokine stromal cell-derived factor $1 \alpha(\mathrm{SDF}-1 \alpha$ or CXCL12) is a major chemotactic factors. CXCR4 is the cell surface receptor for SDF-1, and is expressed on early hematopoietic stem cells (HSC), cardiac stem or precursor cells and endothelial progenitor cells (EPC) [1]. Ma and our study recently demonstrated that SDF-1 is expressed increasedly by the heart immediately after an acute myocardial infarction [4]. And the SDF-1 expression at a time of myocardial infarction (MI) can restore stem cell homing to damaged cardiac tissue [2, 5]. However, the effect of intrinsic SDF-1 upregulated expression is, transient and insufficient for cardiac repair [6].Therefore, forced expression of SDF- $1 \alpha$ by adenoviral gene delivery and SDF- $1 \alpha$ protein increased the recruitment of stem cells to the infarcted heart. In addition, SDF-1 is also an inducer of angiogenesis. SDF-1 promotes not only EPCs (CD133 is one of its characteristic markers) recruitment into the ischemic muscles to promote angiogenesis, but also induces bone marrow derived-c-Kit ${ }^{+}$stem cells to differentiate into EPCs and endothelial cells [7-10]. These findings raise the possibility that SDF-1 has the effects on myocardial structure and function via myogenesis and angiogenesis. However, little information is available about the role of SDF-1 on left ventricular remodeling after MI.

A model of $\mathrm{MI}$ in the rat has been created by Left anterior descending artery (LAD) ligation, which results in severe heart failure characterized by increased cardiac fibrosis and left ventricular (LV) dilation. The purpose of this study was to investigate the following topics: (1) whether SDF-1 results in homing of $\mathrm{c}-\mathrm{Kit}^{+}$cardiac stem cells to the injured myocardium and (2) whether the myoangiogenesis effects of SDF-1 mediated stem cells on left ventricular remodeling.

\section{Methods}

Myocardial infarction model and viral transduction

Myocardial infarction (MI) was performed by the ligation of LAD as described previously [7]. Briefly, male Wistar inbred rats (280-320 g) were anesthetized with ketamine (50 mg/kg IP) and xylazine (10 mg/kg IP) and tracheally ventilated with room air using a columbus ventilator (HX-300, Taimeng Instruments, and Chendu, China). After left lateral thoracotomy in the fourth intercostal space, LAD was ligated. Before chest closure, infarction was confirmed by observation of a demarcation of injury with blanching of the myocardium and electrocardiograph. Experimental animals were randomized for each group. After MI induction, $0.5 \times 10^{10} \mathrm{pfu} / \mathrm{ml}$ of AdV.SDF- 1 were separately injected into six different sites (30 $\mu$ per site) for each MI heart in the AdV.SDF-1 group with a 30-gauge tuberculin syringe. Two injection sites were in the myocardium peri-infarction area and two within the infarction area and Control or AdV.LacZ group received the same MI operation and was injected with an equivalent volume of the cell-free PBS or AdV.LacZ, respectively. The sham group underwent the identical surgery with neither ligation of the coronary artery nor adenovirus injection. Penicillin $(150,000 \mathrm{U} / \mathrm{ml})$ was given intravenously before each operation and buprenorphine hydrochloride $(0.05 \mathrm{mg} / \mathrm{kg})$ was administered subcutaneously twice a day for the first $48 \mathrm{~h}$ after operation.

\section{Peripheral blood analysis}

$0.5 \mathrm{ml}$ blood sample was serially (on days $3,7,14$ and 28) drawn from the tail vein to measure peripheral mononuclear cell count. Total peripheral blood mononuclear cells (PBMNCs) count was determined using a Neubauer hematocytometer (Fisher Scientific) [11].

\section{Western blotting and ELISA}

Three, 7, 14, and 28 days after treatment (each time point, $n=5$ ), rats were killed and peripheral blood $(10 \mathrm{ml})$ was collected to measure plasma levels of stromal cell-derived factor $1 \alpha \quad(\mathrm{SDF}-1 \alpha)$ by enzymelinked immunosorbent assay (ELISA).Myocardium tissue extracts of the infarction area and peri-infarction area were clarified and protein content quantified by Bradford method. Subsequently, the levels of SDF- $1 \alpha$ in the infarction area and peri-infarction area of Myocardium were measured by use of the SDF- $1 \alpha$ (R\&D Systems). And left ventricle tissue extracts were clarified and protein content quantified by Bradford method. Thirty micrograms of the clarified extracts was run in $12 \%$ SDSPAGE followed by transfer to a nitrocellulose membrane. Western analysis was carried out using the following primary antibodies: transforming growth factor- $\beta 1$ (TGF$\beta 1$, tissue inhibitor of metalloproteinase-1 (TIMP-1), TIMP-2 (1:500, Santa Cruz). After extensive washing, immunocomplexes were detected with horseradish peroxidase-conjugated appropriate secondary antibodies followed by enhanced chemiluminescence reaction (KPL, American) [7, 8].

\section{RNA preparation and RT-PCR}

Three, 7, 14, and 28 days after treatment (each time point, $n=5$ ), rats were killed, coronary blood was washed out with saline, the peri-infarction area $(100 \mathrm{mg})$ and infarction area $(100 \mathrm{mg})$ of the heart was removed 
and minced, and total RNA was extracted by the guanidinium thiocyanate-phenol chloroform method. Reverse transcription-polymerase chain reaction (RT-PCR) was performed to determine expression of the myocardial cytokines VEGF, basic-FGF, TGF- $\beta 1$, SDF- $1 \alpha$ and its receptor $\mathrm{CXCR} 4$, stem cell factor receptor $\mathrm{c}$-Kit, and collagen type I and III. The RT-PCR procedure was performed according to the manufacturer's recommendation (RT-PCR Kit, Fermentas Life Science, Ontario, Canada). The primers used in this study are listed in supplement 1. Quantitative RT-PCR was performed using SYBR Green Reaction Mix (Eurogentec) on an ABI PRISM 7900HT Detection System (Applied Biosystems). Each sample was run in duplicate. The expression of each gene within the different tissue samples was quantified relative to GAPDH expression [11].

\section{Measurement of hemodynamics}

Twenty-eight days after treatment, hemodynamic measurements in vivo were performed with the methods as following. Rats were anesthetized with pentobarbital sodium (60 mg/kg, i.p.). A carotid artery and femoral artery were isolated. The two catheters filled with heparinized $(10 \mathrm{U} / \mathrm{ml})$ saline solution were connected to Statham pressure transducer (Gould, Saddle Brook, NJ, USA). The carotid arterial catheter was advanced into the left ventricle to record ventricular pressure for a brief period of time. And the femoral artery catheter was inserted into an isolated femoral artery to monitor mean arterial pressure (BP), and heart rate (HR). These hemodynamic parameters were monitored simultaneously and recorded on a thermal pen-writing recorder (RJG- 4122, Nihon Kohden, Japan) and on an FM magnetic tape recorder (RM-7000, Sony, Tokyo, Japan). Tapes were later played back. After the measurements, the heart was rapidly removed from the killed rats (each group, $n=10-12$ ) [12].

\section{Histology and morphometric measurement}

At day 28 after MI, rat wet weight measured, and then LV function was assessed. The hearts were quickly removed and was cut into six transverse slices from apex to base and processed for histology. Heart infarct size was measured using triphenyltetrazolium chloride (TTC).28 days after MI (each group, $n=6$ ). Briefly, left ventricles were sliced transversely into five to six sections approximately $2 \mathrm{~mm}$ in thickness and incubated for $30 \mathrm{~min}$ in a $1 \%$ solution of buffered TTC at $37^{\circ} \mathrm{C}$. Slices were photographed with a digital camera with magnification in order to identify the infarcted myocardium (unstained by TTC) and the non-ischemic zones (stained brick-red).All measurements were done by two experienced technicians who were blinded to the treatment group. The LV-wall thickness was measured at three widely spaced locations within the scar segment as well as the non-infarcted region for each slide and the average of these multiple measurements were calculated. To estimate an overall degree of ventricular remodeling, expansion index was computed by our previous method. The analyses of LV-wall thickness and expansion index were performed upon two middle slides and the averages were calculated for each heart (each group, $n=6$ ) [12-14].

\section{Immunohistochemistry analysis}

Seven and 28 days after treatment (each time point, $n=5$ ), rats were killed. After quick removal of the hearts, the hearts were immersion fixed in $4 \%$ paraformaldehyde and embedded in optimum cutting temperature (OCT) compound (Fisher Scientific, Fair Lawn). Serial transverse sections of $5 \mu \mathrm{m}$ were cut across the entire long axis of the heart and subsequently mounted on slides.

Double-staining immunofluorescence was performed with specific primary antibodies. Briefly, frozen tissue sections were incubated simultaneously with rabbit antihuman SDF-1 $\alpha$ (hSDF-1 $\alpha, 1: 200, \mathrm{R} \& \mathrm{D}$ Systems) and mouse anti-rat Troponin $\mathrm{T}$ (Cardiac isoform, cTnt, $2 \mu \mathrm{g} / \mathrm{ml}$, Neomarkers), mouse anti-rat c-Kit (1:250, Santa Cruz) and rabbit anti-rat CXCR4 (1:250, Santa Cruz) for $60 \mathrm{~min}$ at room temperature, respectively. After a washing with PBS solution, sections were incubated with a goat anti-mouse conjugated TRITC IgG (1:250, R\&D Systems) for c-Kit and cTnt, and goat anti-rabbit conjugated FITC IgG for CXCR4 and hSDF-1 $\alpha$ (1:100, Santa Cruz). Cellular nucleus was stained with $4^{\prime}$, 6-diamidino2-phenylindole (DAPI, $50 \mu \mathrm{g} / \mathrm{ml}$ ). The numbers of c-Kit and CXCR4 positive cells were analyzed five randomly selected fields of the muscle tissue section per high power field $(200 \times)$ by count method using image pro5.02 [12].

Immunohistology was performed with specific primary antibodies against factor vWF-VIII (1:250, Santa Cruz) and cTnt, respectively. The positive stains were shown as red fluorescence color with TRITC IgG. Capillary density was evaluated by counting the number of capillaries in five randomly selected fields of the muscle tissue section ( $n=5$, each). The value of cTnt positive red fluorescence photodensity was analyzed in five randomly selected fields of the muscle tissue section per high power field $(200 \times)$ by count densitometric method using image pro5.02 $(n=5$, each). 


\section{Collagen volume fraction (CVF)}

To analyze collagen accumulation, Masson's trichrome staining was performed to delineate collagen content as percent of infarction and peri-infarction area. Sixteen separate areas of high power fields $(200 \times)$ in each section were visualized under light microscope and photographed with the same exposure time. The collagen volume fraction $(\mathrm{CVF})$ in the infarction and peri-infarction area was calculated as the percentage of stained tissue in the sum of muscle area and connective tissue by densitometric method using image pro5.02 (each group, $n=6$ ) [15].

Data analysis

The data are expressed as mean \pm SD. Statistical significance between two groups was determined by paired or unpaired Student's $t$-test. Results for more than two experimental groups were evaluated by one-way ANOVA to specify differences between groups. $P$ value 0.05 was considered significantly different.

\section{Results}

SDF- $1 \alpha$ expression assay and peripheral blood mononuclear cells (PBMNCs) count

Representative immunofluorescence-stained sections of the hSDF- $1 \alpha$ expression showed in the infarction area (Fig. 1a, b) of the AdV-SDF-1 group 7 days after MI. SDF1 mRNA expression by RT-PCR after MI was increased in the infarcted cardiac tissues, and the level of SDF-1 mRNA expression was highest in 3 days after MI (Fig. 1c). Importantly, the level of SDF-1 protein expression by ELISA after direct myocardial injection of AdV.SDF-1 was significantly increased in the infarcted myocardium (Fig. 1d). At the same time, there was increase of the SDF1 levels in the serum (Fig. 1e). Concomitantly, the number of PBMNCs was increased on day 3, and then decreased after MI. Furthermore, the number of PBMNCs in AdVSDF-1 group showed a greater increase than the other group on day 3, and was elevated until day 7, then decreased thereafter (Fig. 1f). Thus, there was a prolonged
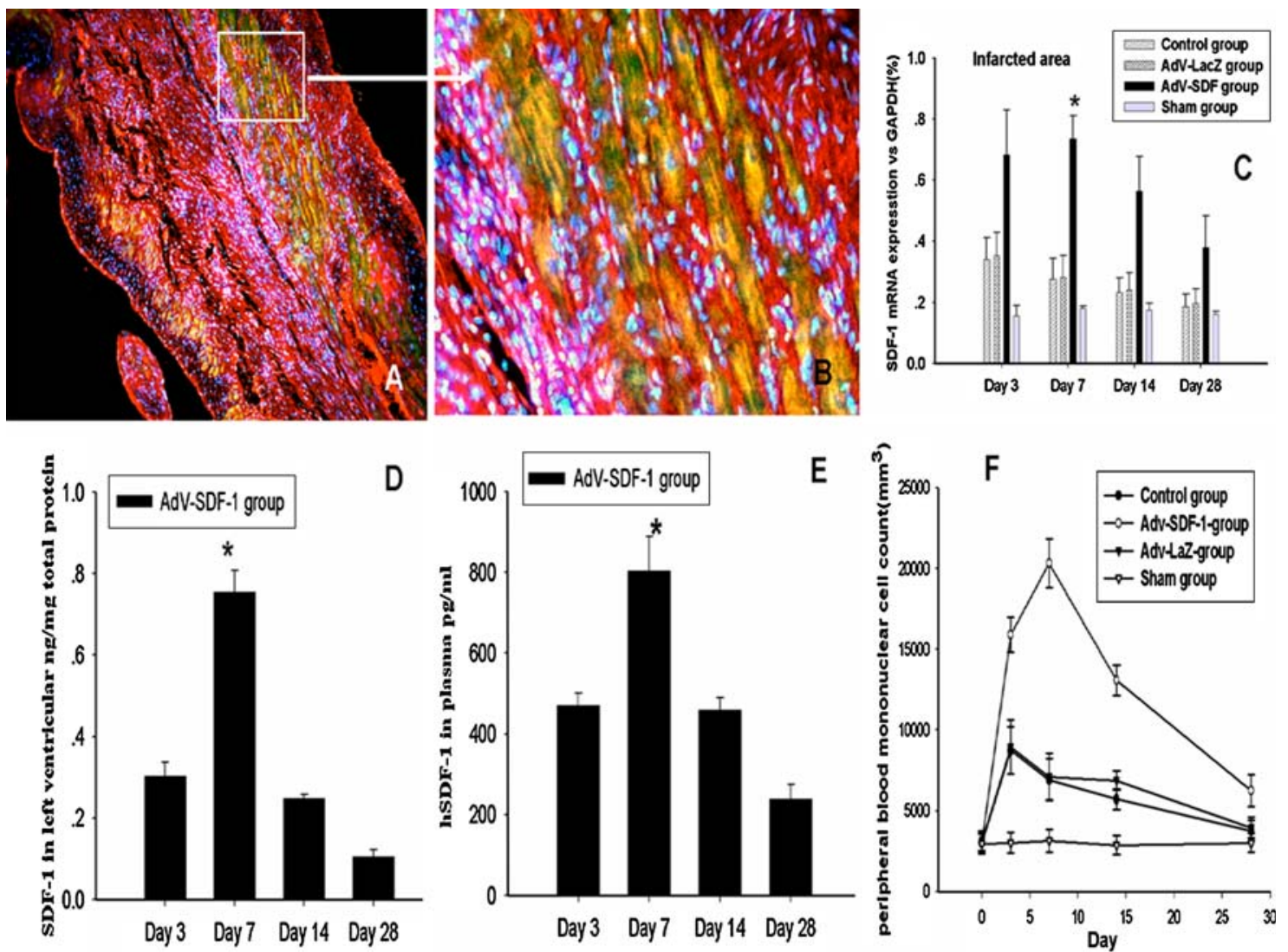

Fig. 1 SDF-1 expression and peripheral blood mononuclear cells (PBMNCs) count. a, b Immunofluorescence staining for hSDF- $1 \alpha$ expression in the infarction area and non-infarction area 7 day after MI.RT-PCR for SDF-1 mRNA expression in different time point after

MI (c). ELISA for SDF-1 levels in heart tissues (d) and serum (e) in the AdV.SDF-1-group. f PBMNCs counts after MI. Values are mean $\pm \mathrm{SD}$. $(n=5$, each). * Denotes $P=0.005$ vs. control group. a $100 \times$; b $400 \times$ 
augmented response of PBMNCs count to SDF-1 after MI induction.

Effect of SDF-1 on stem and progenitor cell homing into myocardium

CXCR4 and c-Kit (CD117) mRNA expression levels increased obviously in the infarcted area of AdV.SDF-1 group compared with control group or AdV.LacZ group. And CXCR4 mRNA expression was greater than c-Kit mRNA expression in the infarcted area of AdV.SDF-1 group (Fig. 2a, b). Simultaneously, the heart tissue sections were immunostained for the presence of c-Kit (CD117) and CXCR4 positive cells in different groups 7 and 28 days after treatment. The numbers of $\mathrm{c}-\mathrm{Kit}^{+}$and $\mathrm{CXCR} 4^{+}$cells were significantly higher in the infarct areas with overexpression of SDF- $1 \alpha$ in the heart of AdV-SDF-1 injection, as compared with the other group (Fig. 2c-e). Furthermore, c-Kit $^{+}$cells were simultaneously $\mathrm{CXCR}^{+}{ }^{+}$(Fig. 2f).

Effect of SDF-1 on surviving cardiocytes and angiogenesis in the heart

The data in Fig. 3 demonstrate that SDF-1, to a greater extent, increase the area and number of cardiac myocytes within the infarct zone (Fig. 3a-d).Semi- quantitation analysis of myocardium in the infracted area showed cTnt density were higher in AdV.SDF-1-group $(P<0.001)$ as compared with the control group and AdV.Lac-Z group (Fig. 3j). The angiogenic effect of SDF-1 overexpression was measured in terms of blood vessel density in the infarct regions after immunostaining for vWF-VIII (Fig. 3e-h). The numbers of blood vessel per area were higher in infarct regions of the AdV.SDF-1-group $(P<0.001)$ as compared with the control group and AdV.Lac-Z group (Fig. 3i).
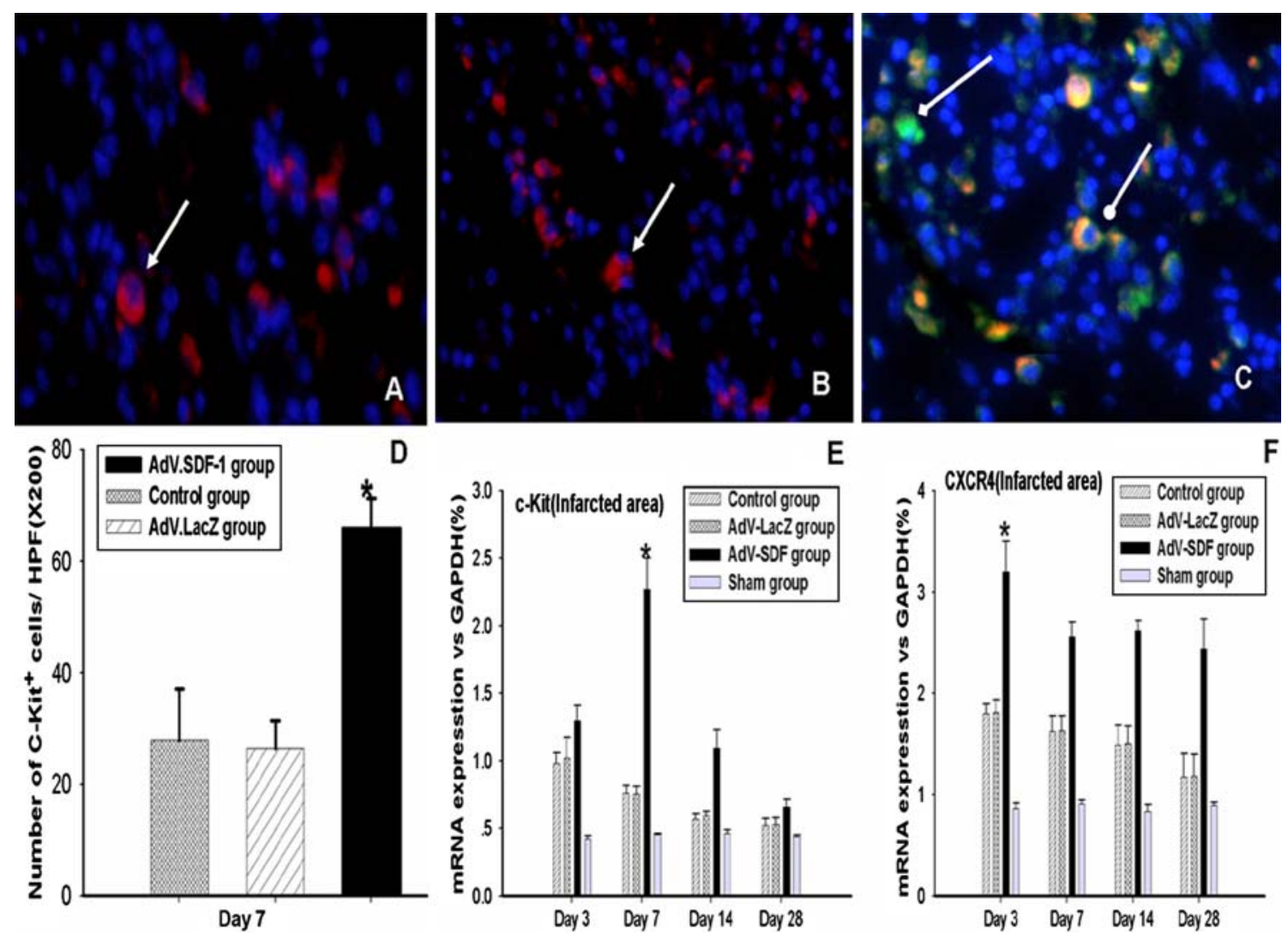

Fig. 2 Representative immunofluorescent staining of homing stem cells in the myocardium infarction area. a, b c-Kit staining 7 days after MI. c-Kit positive cells were observed in the infarction area of the AdV.SDF-1 (a 400×) and control groups (b 400×). c c-Kit and CXCR4 double-staining 7 days after MI $($ c $400 \times)$. c-Kit ${ }^{+}$(arrow indicated), red fluorescence; cellular nucleus marked by DAPI, blue fluorescence; $\mathrm{CXCR}^{+}{ }^{+}$(diamond arrow indicated), green fluorescence. $\mathrm{c}-\mathrm{Kit}^{+} \mathrm{CXCR}^{+}$cells, round arrow indicated. $\mathbf{d}$ The number of ${\mathrm{c}-\mathrm{Kit}^{+}}^{+}$and $\mathrm{CXCR} 4^{+}$cells were analyzed per high power field $(200 \times)$ by count method using image pro5.02, respectively. Data are mean $\pm \mathrm{SD}(n=5$ each). e, f RT-PCR analysis of c-Kit (e) and CXCR4 (f) mRNA expressions in the infarction area. Rat GAPDH served as an internal control. Data are the means of experiments carried out in duplicate. Values are mean $\pm \operatorname{SD}$. $(n=5$, each). * Denotes $P=0.003$ vs. control or AdV.LacZ group 

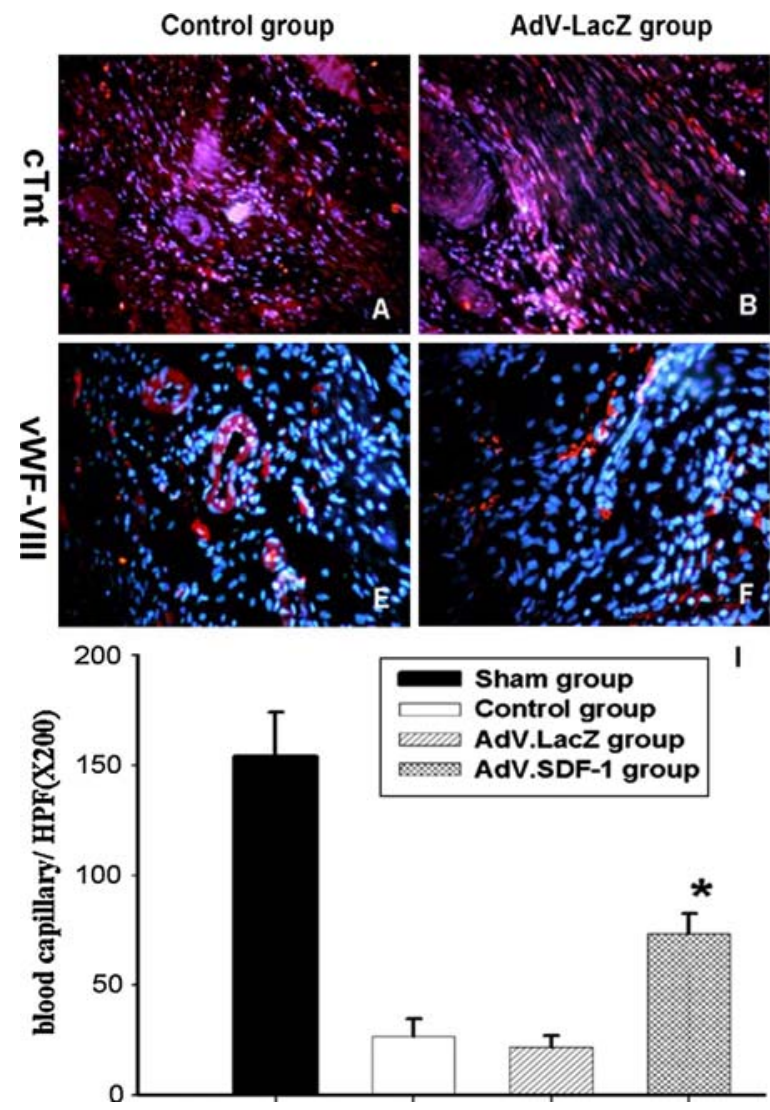

Fig. 3 Immunofluorescent staining of myocardium and blood vessel. a-d cTnt staining 28 days after MI. cTnt positive cells were observed in the infarction area of the control (a), AdV.LacZ (b), AdV.SDF-1 (c) and sham groups (d). e-h Von Willebrand factor (vWF) staining after MI. blood vessel was observed in the infarction area of the control (e), AdV.LacZ (f), AdV.SDF-1 (g) and sham groups (h), respectively. i The number of blood vessel was analyzed per high

However, these above changes were lower than sham group.

\section{Measurement of hemodynamics}

To confirm whether the over-expression SDF-1 in injured myocardium would even further improve cardiac function, we carried out measurement of hemodynamics 28 days after transplantation. Measurement of hemodynamics in vivo showed that LV function was significantly lower in AdV.SDF-1 group, AdV.LaZ group and control group than sham group. However, improvement of LV function was significantly greater in AdV.SDF-1 group than the control group or the AdV.LaZ group. The differences of LVSP $(P<0.05), \pm \mathrm{dp}^{-\mathrm{dt}_{\max }}$ and LVEDP $(P<0.05)$ were statistically significant between the three groups (Table 1).
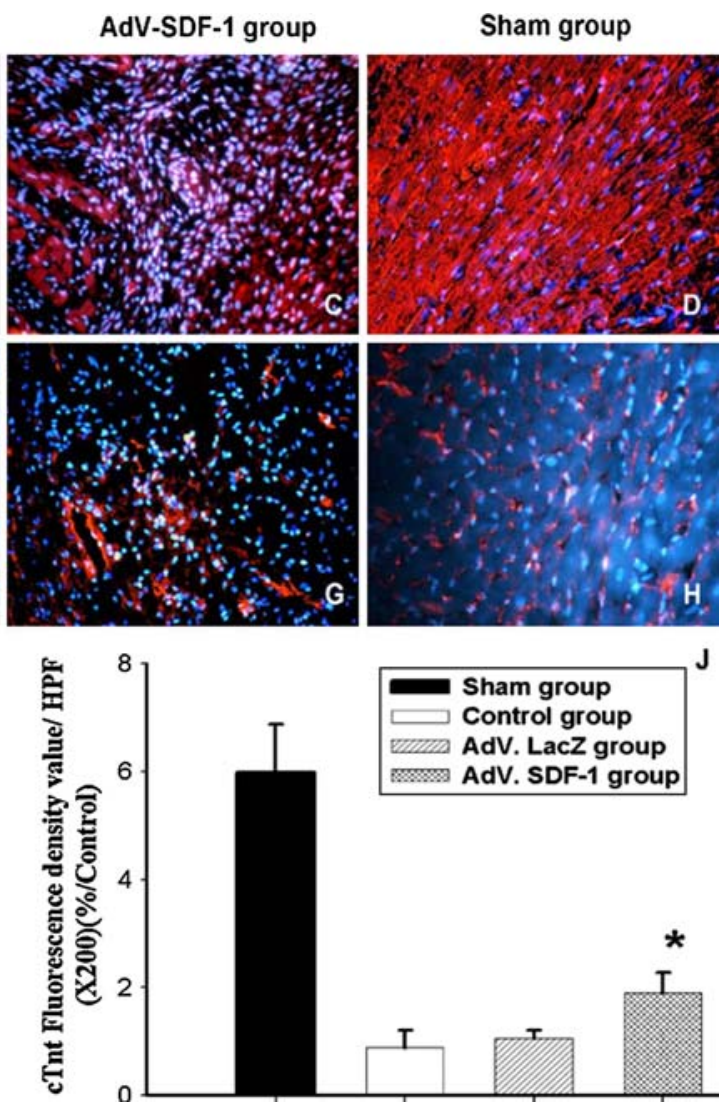

power field $(200 \times)$ by count method using image pro5.02, respectively. Data are mean \pm SEM $(n=5$ each). $\mathbf{j}$ The value of cTnt positive red fluorescence photodensity was analyzed by per high power field $(200 \times)$ by densitometric method using image pro5.02. Data are mean \pm SEM $(n=5$ each $)$. Denotes $P=0.001$ vs. control or AdV.LacZ group

\section{Quantitative RT-PCR analysis}

mRNA expression of TGF $\beta 1$ in the infarcted area of AdV.SDF-1 group, control group and AdV.LacZ group increased obviously compared to that of sham-operated rats, and was peaked on day 3 or 7 up to approximately $2-3$ fold compared to that of sham-operated rats, and then slowly declined. However, TGF $\beta 1$ mRNA expression in the infarcted area of AdV.SDF-1 group also showed no difference or lower levels compared with control group or AdV.LacZ group 7-28 days after treatment (Fig. 4a). Collagen type I and type III mRNA expression levels in the infarcted area of AdV.SDF-1 group, control group and AdV.LacZ group increased obviously compared to that of sham-operated rats. But, Collagen type I and type III mRNA expression levels in the infarcted area of AdV.SDF1 group were lower than the control group or AdV.LacZ group (Fig. 4c, d). Over-expression SDF-1 in AdV.SDF-1 
Table 1 Physiologic and hemodynamic parameters on days 28

\begin{tabular}{lcccc}
\hline & Sham group $(n=11)$ & Control group $(n=10)$ & Adv-SDF-1 group $(n=12)$ & Adv-LacZ group $(n=10)$ \\
\hline HVW/BW $(\mathrm{mg} / \mathrm{g})$ & $2.146 \pm 0.30$ & $1.88 \pm 0.22$ & $2.02 \pm 0.43$ & $1.85 \pm 0.32$ \\
HR (BMP) & $402 \pm 11$ & $375 \pm 16$ & $394 \pm 15$ & $379 \pm 17$ \\
LVSP $(\mathrm{mmHg})$ & $120 \pm 3.1$ & $91 \pm 3.71$ & $106 \pm 4.3 *$ & $92 \pm 4.1$ \\
LVEDP $(\mathrm{mmHg})$ & $3.25 \pm 0.53$ & $14.86 \pm 0.97$ & $10.01 \pm 0.71^{* \#}$ & $13.97 \pm 0.98$ \\
$+\mathrm{dP}^{*} \mathrm{dt}_{\max }(\mathrm{mmHg} / \mathrm{s})$ & $7,781 \pm 252$ & $2,870 \pm 129$ & $4,330 \pm 26$ * $^{*}$ & $2,967 \pm 131$ \\
$-\mathrm{dP}_{\mathrm{dt}}(\mathrm{mmHg} / \mathrm{s})$ & $6,634 \pm 231$ & $1,927 \pm 177$ & $3,624 \pm 295^{*}$ & $2,023 \pm 105$ \\
\hline
\end{tabular}

$+\mathrm{dP} / \mathrm{dt}_{\max }$ and $-\mathrm{dP} / \mathrm{dt}_{\max }$ rate in rise and fall of ventricular pressure, respectively. Data are mean $\pm \mathrm{SEM}(n=7-10)$

$H V W$ heart ventricular weight, $B W$ body weight, $L V S P$ left ventricular systolic pressure, LVEDP left ventricular end-diastolic pressure

* Denotes $P<0.005$ vs. control group

\# Denotes $P<0.005$ vs. sham group
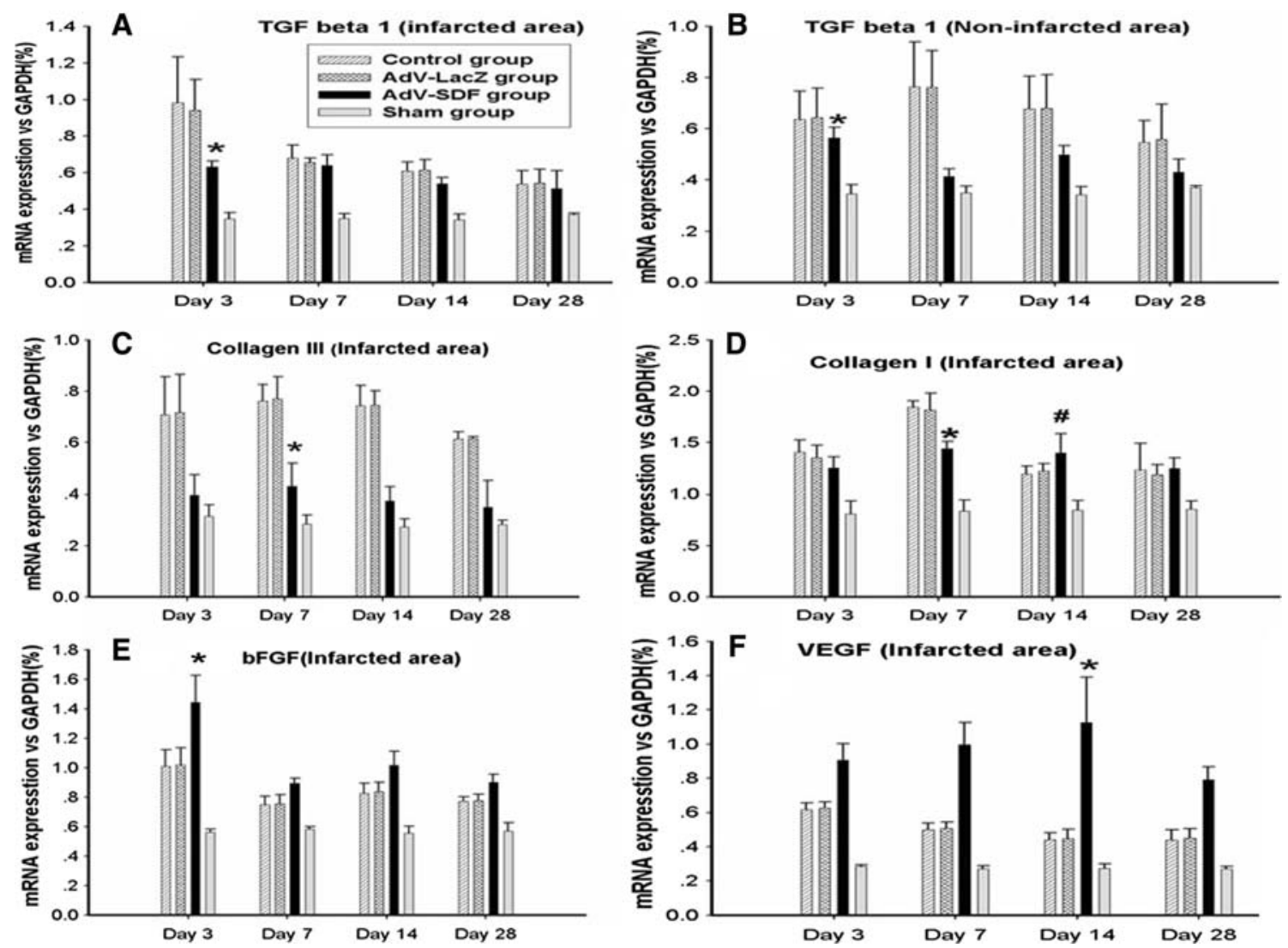

Fig. 4 SYBR Green real-time PCR analysis of TGF- $\beta 1$ in infarcted (a) and noninfarcted (b) myocardium, and of collagen type I (c), type III (d), bFGF (e) and VEGF (f) mRNA expression in infarcted myocardium. Data were processed with a specially designed software program based on $\mathrm{Ct}$ values of each sample and normalized to GAPDH. Bars represent mRNA levels relative to GAPDH mRNA

level for control, AdV.LacZ, AdV.SDF-1 and sham group. Data are the means of experiments carried out in duplicate. Values are mean \pm SD. ( $n=5$ each). $* P=0.002$ vs. control or AdV.LacZ group. $V E G F$ vascular endothelial growth factor, basic-FGF basic fibroblast growth factor

group increased the expression of VEGF and bFGF mRNA analyzed in the myocardium infarction area (Fig. 4) after MI, and VEGF and bFGF expression increased obviously in 3 day after MI and continued until 7-28 days after MI.

Western blot analysis

Levels of TIMP-1, TIMP- 2 and TGF- $\beta 1$ proteins in the infarcted area at different time point were analyzed by Western blotting. There was an increase in TIMP-1, TIMP- 
Fig. 5 Western blotting analysis of TGF- $\beta_{1}$, TIMP- 1 and TIMP-2 in infarcted myocardium. Bars represent protein levels relative to $\beta$-tubin for control group, sham group and AdV-SDF-1 group. Data are the means of experiments carried out in duplicate. Values are mean $\pm \mathrm{SD}$. * Denotes $P=0.004$ vs. sham or control group $(n=5$ each $)$
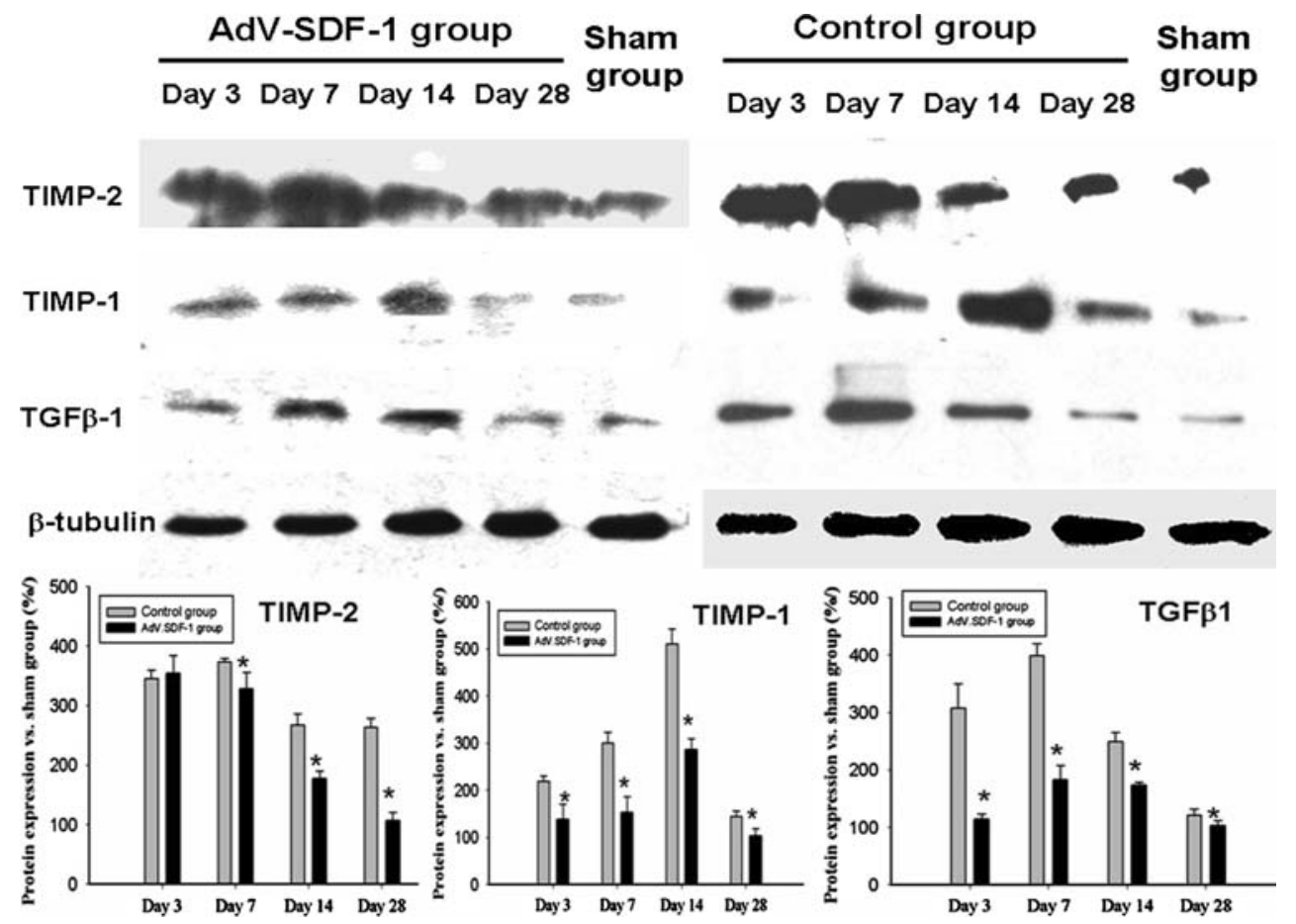

2 and TGF- $\beta 1$ protein in the infarcted area in both the AdV.SDF-1 group and control group compared to sham group at each time point. Highest TIMP-1, TIMP-2 and TGF- $\beta 1$ expression was noted on day 14,7 or 7 in different group, respectively. However, there was a decrease in TGF- $\beta 1$, TIMP- 1 and TIMP-2 protein in the infarcted area in the AdV.SDF-1 group compared to the control group at each time point (Fig. 5). And above these changes were no difference between the control group and AdV.LacZ group (data not shown).

Effect of SDF-1 on heart histology and morphology

Representative picture of myocardial infarction 28 days after surgery (Fig. 6a-d). As shown in Fig. 7 g, k, new or survivaling myocardium was located either in the middle of the scar or adjacent to the border zone. This type of pattern was not observed in any of the hearts that received medium injection only or AdV-LacZ. In contrast, the infarcted area in control group and AdV-LacZ group showed transmural and thin scar tissue composed of collagen (Fig. 5e, f). Representative Masson's trichrome-stained sections showed more collagen accumulation in the infarcted area and peri-infarction area 28 day after $\mathrm{MI}$ in control group or AdV-LacZ group (Fig. 5i, j) than AdV-SDF-1 group (Fig. 5k), semi-quantitative analysis indicated that collagen volume fraction in the infarcted area was significantly decreased in AdV-SDF-1 group compared to control group or AdV-LacZ group (Fig. 7a). Marked increases in the average LV wall thickness were also observed in the
AdV-SDF-1 hearts (Fig. 7b). Moreover, infarct size was significantly reduced in AdV-SDF-1 group as compared with the control group (Fig. 7c). Quantitative analysis of cavitary dilatation and wall thickness in all hearts of three groups revealed that AdV-SDF-1 injection animals displayed significantly less ventricular dilation than control group or AdV-LacZ group. The expansion index was significantly lower in AdV-SDF-1 group than in control group (Fig. 7d).

\section{Discussion}

Presently, isolation of cardiac stem cells was based exclusively on the expression of a stem cell-related surface antigen: c-kit and Sca-1. Freshly isolated c-kit ${ }^{+} \mathrm{Lin}^{-}$cells from heart were found to be self-renewing, clonogenic, and multi-potent, exhibiting biochemical differentiation into the myogenic cell, smooth muscle cell, or endothelial cell lineage $[1-3,16]$. Interestingly, Sca- ${ }^{+}$c-Kit ${ }^{-}$cells from mice hearts were induced in vitro to differentiate toward the cardiac myogenic lineage in response to $5^{\prime}$-azacytidine [17]. Obviously, cardiac stem cells appear to be a mixture of different subpopulations. In this study, we selected the marker: c-Kit as identification index of cardiac stem cell, and $\mathrm{c}-\mathrm{Kit}^{+}$cells in the damaged heart were observed. We found $\mathrm{c}-\mathrm{Kit}^{+}$cells increased significantly in the Adv-SDF1 group than the other group, which were directly mediated by SDF-1/CXCR4.

It is interesting that Ratajczak et al. have reported that cells expressing early cardiac markers reside in the bone 

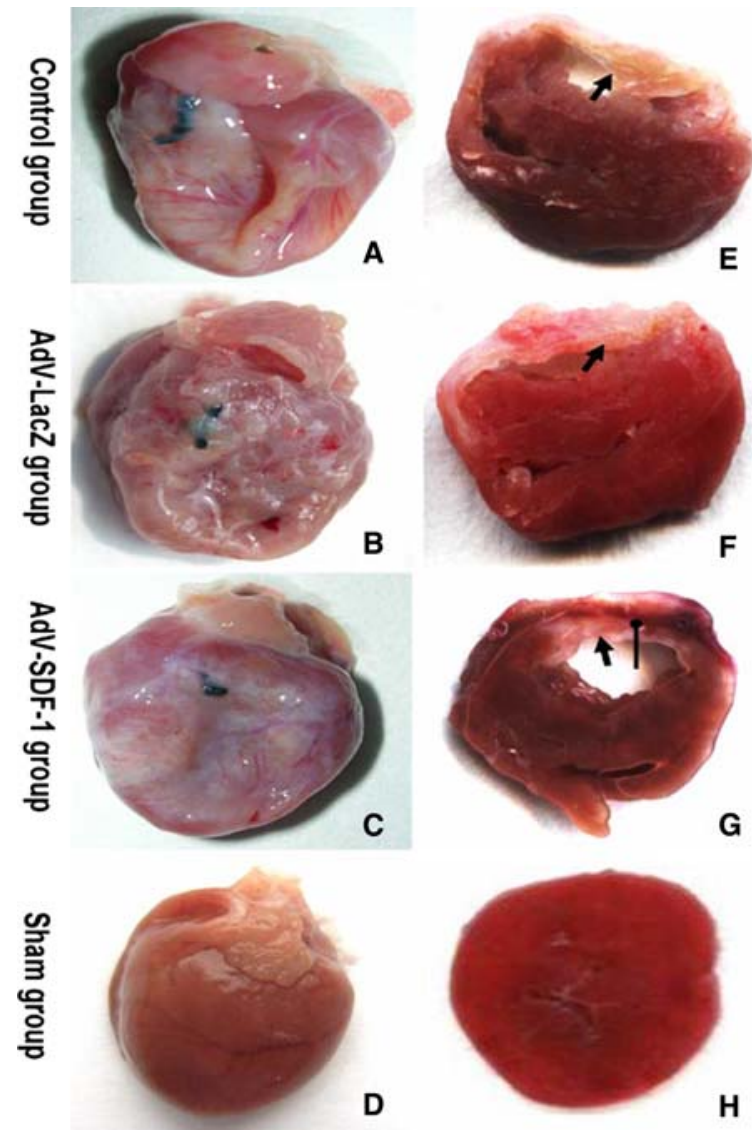

Fig. 6 Effects of SDF-1 on histology and form. a-d Representative picture of a myocardial infarction 28 days after surgery, the heart was exercised, and infarction size was measured by TTC $(3 \times)$. e-h The infarcted myocardium was unstained by TTC (white, arrow indicated), and the non-ischemic zones stained brick red. i-p Representative Masson's trichrome-stained sections in the area of infarcted left

marrow and are mobilized into the peripheral blood after myocardial infarction. Furthermore, Cimini' study indicated that interventions that increase the infiltration of bone marrow derived c-kit ${ }^{+}$cells to the infarcted heart could potentiate this endogenous repair response, prevent infarct expansion, and improve the recovery of cardiac function after MI [18]. However, some studies showed the characteristic of $\mathrm{c}-\mathrm{Kit}^{+}$cells derived from heart and bone marrow is different $[1-3,16,17]$. And in this study, we found cardiogenic $\mathrm{c}-\mathrm{Kit}^{+}$cells could spontaneously differentiate into cardiomyocytes in vitro, but bone marrow derived c$\mathrm{Kit}^{+}$cells could not spontaneously differentiate into cardiomyocytes, bone marrow derived $\mathrm{c}-\mathrm{Kit}^{+}$cells could differentiate into cardiomyocytes when co-cultured with cardiomyocytes in vitro [supplement 3]. Although we did not confirm whether these $\mathrm{c}-\mathrm{Kit}^{+}$cells derived from bone marrow or heart or not, cadiocytes in infarction and periinfarction area increased significantly in the Adv-SDF-1 group than the control or Adv-LacZ group. These data

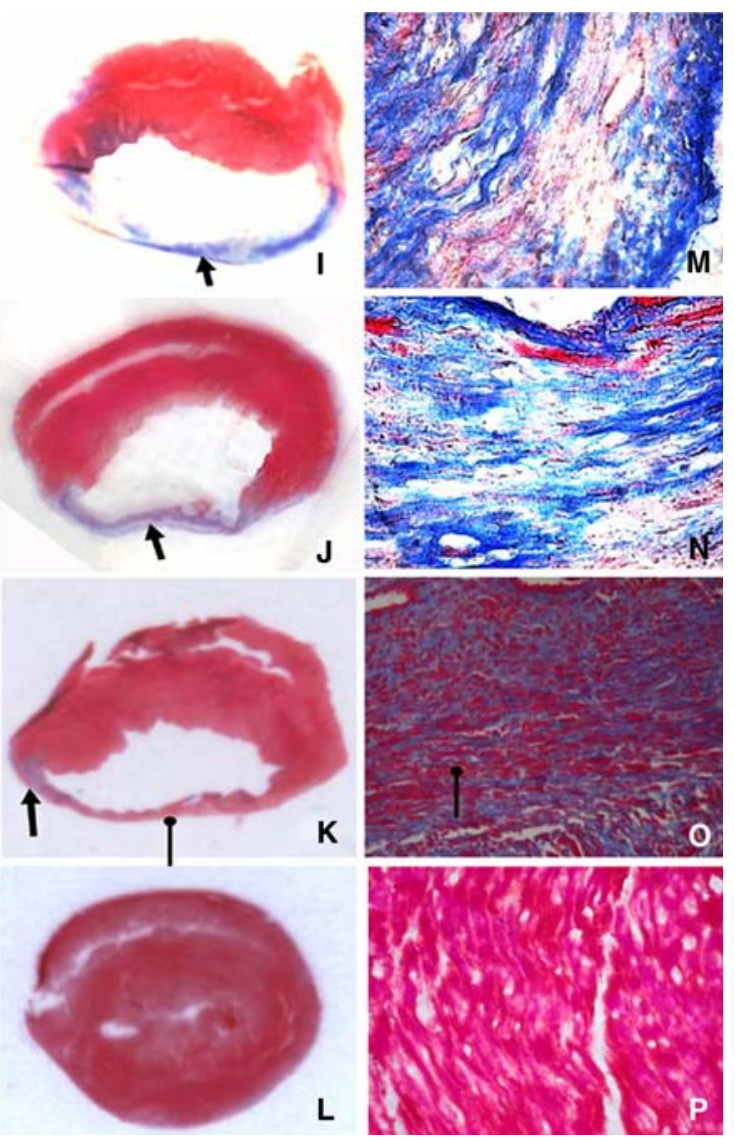

ventricular tissue 28 days after MI (blue, collagen, black arrow indicated; i-l $3 \times ; \mathbf{m}-\mathbf{p} 400 \times$ ). There was a decreased infarct size, thicker LV wall in the AdV.SDF-1 group. The new or survivaling myocardium (black round arrow indicated) typically appeared as redpositive cells wedged between an inner and outer layer of collagen (each group, $n=6$ ) (Color figure online)

suggested the part of these cardiocytes could derive from c-Kit ${ }^{+}$cardiac stem cells. In addition, SDF-1 has been recently shown to have additional non-stem cell-recruiting effects, including increasing stem cell survival. Our and Zhang'studies showed SDF-1 to the cell surface of injured cardiac myocytes could lead to inhibition of cardiocytes apoptosis via SDF-1 inducing up-regulation of prosurvival signaling $[19,20]$. Therefore, these changes could lead to decrease scar sizes, reduce remodeling and improve cardiac function, which is a consequence of the increased cardiocytes in damaged heart sites.

It is interesting that our study have showed c-Kit ${ }^{+}$stem cells differentiation into endothelial cells were related with the presence of SDF-1 in vitro [supplement 3]. Recently, Falco et al. [21] have shown that SDF-1 plays an important role in differentiation of bone marrow-derived $\mathrm{c}-\mathrm{kit}^{+}{ }^{+}$stem cells into EPCs and endothelial cells. More importantly, Fazel et al. [22] have shown that bone marrow c-kit ${ }^{+}$cells act as key regulators of the angiogenic switch in infarcted 

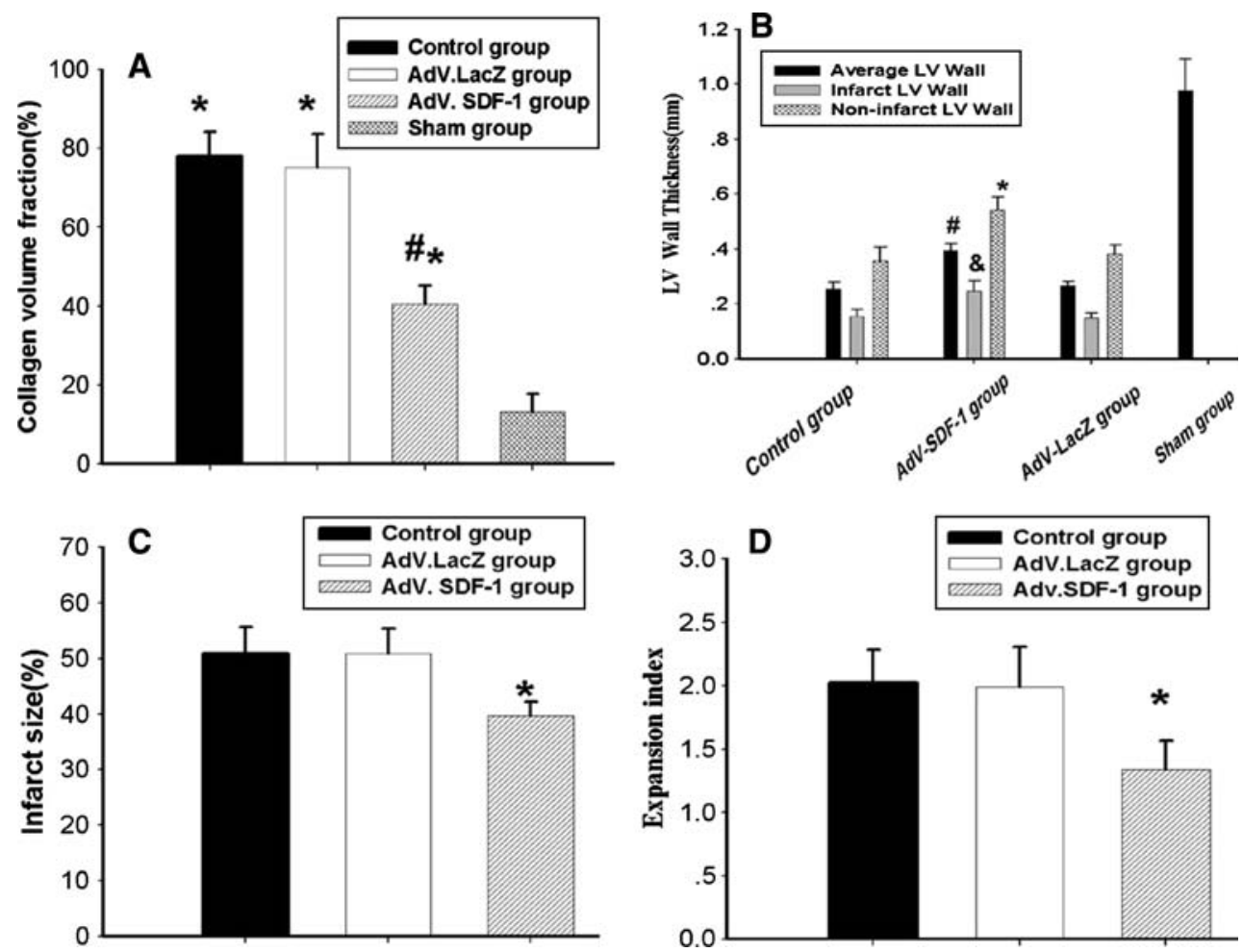

Fig. 7 Effects of SDF-1 on infarct size and left ventricle wall thickness. a Quantitation of collagen content in percent of infarct and noninfarcted area in multiple fields. $\mathbf{b}$ Thickness of infarct LV wall in AdV.SDF-1 group is obviously thicker than the infarct LV wall in the control and AdV.Lac-Z group. Thickness of infarct LV wall in AdV.SDF-1 group is thinner than the non-infarct LV wall $\left({ }^{\&} P=0.001\right)$ and is obviously thicker than the infarct LV wall in the control or AdV.Lac-Z group ( $\left.{ }^{\&} P=0.0005\right)$. The average LV wall in the AdV.SDF-1 group is thicker than in the control or

myocardium, and SDF-1 promote angiogenesis by enhancement of EPCs incorporation into new vessels [23]. Furthermore, these stem cells produce a wide array of arteriogenic cytokines and improve perfusion and remodeling in mouse models of hindlimb ischemia, and these effects appear to be mediated through paracrine mechanisms associated with local release of the arteriogenic cytokines [22, 24-26]. In our study, VEGF expression level in the AdV-SDF-1 group obviously increased. Increased VEGF could involve in or trigger angiogenic progress of stem cells, even might contribute to postnatal neovascularization by mobilizing bone marrow-derived stem cells [7-9, 21, 24, 27, 28]. Of course, besides VEGF, released angiogenic cytokines after MI include fibroblast growth factor (FGF), hepatocyte growth factor (HGF), and so on [28]. For example, Rosenblatt-Velin et al. [29] recently reported that bFGF controls the differentiation of resident cardiac precursors into functional cardiomyocytes. And other angiogenic factors contribute to angiogenesis in the damaged sites $[30,31]$.Therefore; these cytokines could

AdV.Lac-Z group ( $\left.{ }^{\#} P=0.001\right)$ and thinner than in the sham group ( ${ }^{\#} P=0.0003$ ). The non-infarct LV wall in the AdV.SDF-1 group is thinner than in the sham group (* $P=0.002)$ and thicker than in the control or AdV.Lac-Z group ( $* P=0.0003)$. c There were statistically significant differences in infarct size among the control, AdV.Lac-Z and AdV.SDF-1 groups (mean \pm SD). (* $P=0.0006$ ). d Expansion index analyses in AdV.SDF-1 group showed lower than control or AdV.Lac-Z group (each group, $n=6$ )

contribute to stem cell-mediated regeneration repair of infarcted myocardium.

In our study, we evaluated the functional improvement seen in AdV.SDF-1 group by cardiac catheterization to detect ventricular pressure. The AdV.LacZ group and control group showed the expected decline in $\pm \mathrm{dp} / \mathrm{dt}_{\max }$ and LVSP, and markedly increase in LVEDP. In contrast, and as expected, The AdV.SDF-1 group showed the lower decline in $\pm \mathrm{dp} / \mathrm{dt}_{\max }$ and LVSP, and the lower increase in LVEDP. Overexpressing SDF-1 contributed to preservation of $\pm \mathrm{dp} / \mathrm{dt}_{\max }$, LVSP and LVEDP in infarct hearts. Also, histology and morphometric measurement showed the expected decrease in infarcted size (IS), and obviously increase in LV wall thickness in AdV.SDF-1 group. And SDF-1 overexpressing hearts were less dilated and a combination of less dilatation and a trend toward less paradoxical systolic bulging probably led to the improved ventricular pressure. Furthermore, overexpressing SDF-1 could inhibit LV remodeling, augment or preserve the myocardial elasticity, improve heart function and reduce 
the expression of extracellular matrix genes (eg: Collagen, et al.). These change of morphous and structure is related with the increasing of the area and number of cardiac myocytes within the infarct zone.

More Recently, Shao et al. [23] reported that SDF-1 promoted angiogenesis by enhancement of EPCs incorporation into new vessels, which was related with upregulation and activation of matrix metalloproteinase-2 (MMP) and MMP-9. However, TIMP-2 bound to the membrane in a hydroxamate insensitive manner specially inhibits MMP-2 activated by the membrane, but not other MMPs. Similarly, TIMP-1 inhibits MMP-9 activation [32]. Interestingly, TIMP-1 overexpression in pancreatic cancer cells reduced angiogenesis and cell implantation, this anti-angiogenic activity of TIMP-1 involved in part MMP-inhibition [33]. TIMP-2 mediated inhibition of angiogenesis was an MMPindependent mechanism [34]. Furthermore, TIMPs can block the angiogenic process at different stages and the acquisition of an angiogenic phenotype may involve the suppression of TIMPs expression [32]. For example, TIMPs can inhibit bFGF-induced human endothelial cell growth [35]. In our study, we observed that expression of Tissue inhibitors of metalloproteinases (TIMP1,2) decreased in infarction area of myocardium in the AdV-SDF-1 group, which was concordance with much more stem cells and blood vessels. These data suggested that angiogenesis induced by SDF-1 could involve in TIMPs down-regulation and MMPs up-regulation, which would not only contribute to create a favorable tissue environment for stem cells migration, but also promote angiogenesis.

Moreover, TIMPs as multifunctional proteins involved in LV remodeling. Koch et al. reported that SDF-1 through transendocardial delivery promoted the degradation of collagen in peri-infarct area [18]. Collagen synthesis, which is promoted by TGF- $\beta 1$, has different significance in infarcted and noninfarcted areas [36]. Our current study suggested that TGF- $\beta 1$ down-regulation caused by SDF- 1 was associated with decreased collagen accumulation and down-regulated TIMP-1 expression in the infarction area. Although production of fibrosis after MI prevents structural fragility. Previous studies reported that a MMP family was increased in the postinfarction heart failure models with permanent occlusion and large infarction and that the inhibitors beneficially affected cardiac remodeling and function [36, 37]. Furthermore, myocardial TIMP-1 plays a regulatory role in post-MI remodeling and the accelerated myocardial remodeling induced by TIMP-1 gene deletion can be pharmacologically "rescued" by MMP inhibition [38]. Thus, it is suggested that a decrease in TIMPs has an aggravating effect on heart failure via collagen degradation. However, it is well known that the volume of reactive granulation and/or scar tissues after skin injury after burn, surgery, etc, frequently becomes excessive, and this is called hypertrophic scarring. The excessive extent of fibrosis without contractility or relaxation would accelerate cardiac remodeling and decrease cardiac function, as seen in ischemic or idiopathic dilated cardiomyopathy. Furthermore, an increase in MMPs by hepatocyte growth factor or G-CSF was beneficial on post-MI heart failure via its anti-fibrotic action; reduction of scar tissue and improvement of remodeling were observed simultaneously in myocardial regeneration therapy [23, 39-41]. In addition, in the setting of liver injury, MMP-9 is associated with increased CXCR4 expression on stem cells, and MMP inhibitors reduce homing of these cells to the liver [42, 43]. Although SDF-1 is cleaved by exopeptidases and matrix metalloproteinase-2, a new, protease-resistant SDF-1 and nanofiber-mediated delivery promoted recruitment of stem cells and improved cardiac function after myocardial infarction [44]. Thus, in the present study, the beneficial effect of SDF-1 over expression relies on a higher number of cardiocytes and blood vessels and down-regulation of TIMPs and increased participation of mobilized stem cells, which supports the concept of myocardial repair mediated by stem cells after infarction.

\section{Conclusion}

our data are consistent with the concept that there is a naturally occurring regenerative repair process that occurs in infarcted myocardium that can be enhanced through the over-expression of SDF- $1 \alpha$ within the myocardium after MI. Over-expressing SDF- $1 \alpha$ improved cardiac structure and function through the symphysial effect of myogenesis and angiogenesis.

Acknowledgments This study was supported by grants from National natural Science Foundation of China (30700306), Hubei Natural Science Foundation (2005ABA079), Hubei Health Department Science Foundation (JX3B29), Hubei Education Department Science Foundation (Q200524003, B200624006), YunYang Medical College Science Foundation (2005QDJ01), and Shiyan Ren min hospital Science Foundation, China.

Open Access This article is distributed under the terms of the Creative Commons Attribution Noncommercial License which permits any noncommercial use, distribution, and reproduction in any medium, provided the original author(s) and source are credited.

\section{References}

1. Annarosa L, Jan K, Piero A (2005) Cardiac stem cells and mechanisms of myocardial regeneration. Physiol Rev 85:13731416. doi:10.1152/physrev.00013.2005

2. Oh H, Bradfute SB, Gallardo TD, Nakamura T, Gaussin V, Mishina $Y$ et al (2003) Cardiac progenitor cells from adult 
myocardium: homing, differentiation, and fusion after infarction. Proc Natl Acad Sci USA 100(21):12313-12318. doi:10.1073/ pnas. 2132126100

3. Dawn B, Stein AB, Urbanek K, Rota M, Whang B, Rastaldo R et al (2005) Cardiac stem cells delivered intravascularly traverse the vessel barrier, regenerate infarcted myocardium, and improve cardiac function. Proc Natl Acad Sci USA 102(10):3766-3771. doi:10.1073/pnas.0405957102

4. Ma J, Ge J, Zhang S, Sun A, Shen J, Chen L et al (2005) Time course of myocardial stromal cell-derived factor 1 expression and beneficial effects of intravenously administered bone marrow stem cells in rats with experimental myocardial infarction. Basic Res Cardiol 100(3):217-223. doi:10.1007/s00395-005-0521-z

5. Mouquet F, Pfister O, Jain M, Oikonomopoulos A, Ngoy S, Summer R et al (2005) Restoration of cardiac progenitor cells after myocardial infarction by self-proliferation and selective homing of bone marrow-derived stem cells. Circ Res 97(11): 1090-1092. doi:10.1161/01.RES.0000194330.66545.f5

6. Elmadbouh I, Haider HK, Jiang S, Idris NM, Lu G, Ashraf M (2007) Ex vivo delivered stromal cell-derived factor-1 alpha promotes stem cell homing and induces angiomyogenesis in the infarcted myocardium. J Mol Cell Cardiol 42(4):792-803. doi: 10.1016/j.yjmcc.2007.02.001

7. Abbott JD, Huang Y, Liu D, Hickey R, Krause DS, Giordano FJ (2004) Stromal cell-derived factor-1 alpha plays a critical role in stem cell recruitment to the heart after myocardial infarction but is not sufficient to induce homing in the absence of injury. Circulation 110(21):3300-3305. doi:10.1161/01.CIR.0000147780. 30124.CF

8. Hiasa K, Ishibashi M, Ohtani K, Inoue S, Zhao Q, Kitamoto S, Sata M, Ichiki T, Takeshita A, Egashira K (2004) Gene transfer of stromal cell-derived factor- 1 alpha enhances ischemic vasculogenesis and angiogenesis via vascular endothelial growth factor/endothelial nitric oxide synthase-related pathway: nextgeneration chemokine therapy for therapeutic neovascularization. Circulation 109(20):2454-2461. doi:10.1161/01.CIR.0000128213. 96779.61

9. Yamaguchi J, Kusano KF, Masuo O, Kawamoto A, Silver M, Murasawa S, Bosch-Marce M, Masuda $\mathrm{H}$, Losordo DW, Isner JM, Asahara T (2003) Stromal cell-derived factor-1 effects on ex vivo expanded endothelial progenitor cell recruitment for ischemic neovascularization. Circulation 107(9):1322-1328. doi: 10.1161/01.CIR.0000055313.77510.22

10. Urbanek K, Torella D, Sheikh F, De Angelis A, Nurzynska D, Silvestri $F$ et al (2005) Myocardial regeneration by activation of multipotent cardiac stem cells in ischemic heart failure. Proc Natl Acad Sci USA 102(24):8692-8697. doi:10.1073/pnas.0500169102

11. Kuhlmann MT, Kirchhof P, Klocke R, Hasib L, Stypmann J, Fabritz L et al (2006) G-CSF/SCF reduces inducible arrhythmias in the infarcted heart potentially via increased connexin 43 expression and arteriogenesis. J Exp Med 203(1):87-97. doi: 10.1084/jem.20051151

12. Tang JM, Xie QY, Pan GD, Wang JN, Wang MJ (2006) Mesenchymal stem cells participate in angiogenesis and improve heart function in rat model of myocardial ischemia with reperfusion. Eur J Cardiothorac Surg 30(2):353-361. doi:10.1016/ j.ejcts.2006.02.070

13. Yao M, Dieterle T, Hale SL, Dow JS, Kedes LH, Peterson KL, Kloner RA (2003) Long-term outcome of fetal cell transplantation on postinfarction ventricular remodeling and function. J Mol Cell Cardiol 35(6):661-670. doi:10.1016/S0022-2828(03)00098-1

14. Hochman JS, Choo H (1987) Limitation of myocardial infarct expansion by reperfusion independent of myocardial salvage. Circulation 75(1):299-306

15. Koch KC, Schaefer W, Liehn E, Rammos C, Mueller D, Schroeder J et al (2006) Effect of catheter-based transendocardial delivery of stromal cell-derived factor $1 \alpha$ on left ventricular function and perfusion in a porcine model of myocardial infarction. Basic Res Cardiol 101(1):69-77. doi:10.1007/s00395-0050570-3

16. Bearzi C, Rota M, Hosoda T, Tillmanns J, Nascimbene A, De Angelis A et al (2007) Human cardiac stem cells. Proc Natl Acad Sci USA 104(35):14068-14073. doi:10.1073/pnas.0706760104

17. Messina E, De Angelis L, Frati G, Morrone S, Chimenti S, Fiordaliso $\mathrm{F}$ et al (2004) Isolation and expansion of adult cardiac stem cells from human and murine heart. Circ Res 95(9):911921. doi:10.1161/01.RES.0000147315.71699.51

18. Cimini M, Fazel S, Zhuo S, Xaymardan M, Fujii H, Weisel RD, Li RK (2007) c-kit dysfunction impairs myocardial healing after infarction. Circulation 116(Suppl 11):I77-I82. doi:10.1161/ CIRCULATIONAHA.107.708107

19. Tang J, Wang J, Yang J, Kong X (2008) Adenovirus-mediated stromal cell-derived- factor-1 alpha gene transfer induces cardiac preservation after infarction via angiogenesis of CD133+ stem cells and anti-apoptosis. Interact Cardiovasc Thorac Surg 7(5): 767-770. doi:10.1510/icvts.2007.169896

20. Zhang M, Mal N, Kiedrowski M, Chacko M, Askari AT, Popovic ZB et al (2007) SDF-1 expression by mesenchymal stem cells results in trophic support of cardiac myocytes after myocardial infarction. FASEB J 21(12):3197-3207. doi:10.1096/fj.06-6558com

21. De Falco E, Porcelli D, Torella AR, Straino S, Iachininoto MG, Orlandi A, Truffa S, Biglioli P, Napolitano M, Capogrossi MC, Pesce M (2004) SDF-1 involvement in endothelial phenotype and ischemia-induced recruitment of $\mathrm{BM}$ progenitor cells. Blood 104(12):3472-3482. doi:10.1182/blood-2003-12-4423

22. Fazel S, Cimini M, Chen L, Li S, Angoulvant D, Fedak P et al (2006) Cardioprotective c-kit ${ }^{+}$cells are from the bone marrow and regulate the myocardial balance of angiogenic cytokines. $\mathrm{J}$ Clin Invest 116(7):1865-1877. doi:10.1172/JCI27019

23. Shao H, Tan Y, Eton D, Yang Z, Uberti MG, Li S, et al. (2008) Statin and stromal cell derived factor-1 additively promote angiogenesis by enhancement of progenitor cells incorporation into new vessels. Stem Cells 26(5):1376-1384

24. Urbich C, Aicher A, Heeschen C, Dernbach E, Hofmann WK, Zeiher AM, Dimmeler S (2005) Soluble factors released by endothelial progenitor cells promote migration of endothelial cells and cardiac resident progenitor cells. J Mol Cell Cardiol 39(5):733-742. doi:10.1016/j.yjmcc.2005.07.003

25. Kinnaird T, Stabile E, Burnett MS, Lee CW, Barr S, Fuchs S et al (2004) Marrow-derived stromal cells express genes encoding a broad spectrum of arteriogenic cytokines and promote in vitro and in vivo arteriogenesis through paracrine mechanisms. Circ Res 94:678-685. doi:10.1161/01.RES.0000118601.37875.AC

26. Miyamoto Y, Suyama T, Yashita T, Akimaru H, Kurata H (2007) Bone marrow subpopulations contain distinct types of endothelial progenitor cells and angiogenic cytokine-producing cells. J Mol Cell Cardiol 43(5):627-635. doi:10.1016/j.yjmcc.2007. 08.001

27. Asahara T, Takahashi T, Masuda H, Kalka C, Chen D, Iwaguro $H$ et al (1999) VEGF contributes to postnatal neovascularization by mobilizing bone marrow-derived endothelial progenitor cells. EMBO J 18:3964-3972. doi:10.1093/emboj/18.14.3964

28. Vandervelde S, van Luyn MJ, Tio RA, Harmsen MC (2005) Signaling factors in stem cell-mediated repair of infarcted myocardium. J Mol Cell Cardiol 39:363-376. doi:10.1016/j.yjmcc. 2005.05.012

29. Rosenblatt-Velin N, Lepore MG, Cartoni C, Beermann F, Pedrazzini T (2005) FGF-2 controls the differentiation of resident cardiac precursors into functional cardiomyocytes. J Clin Invest 115:1724-1733. doi:10.1172/JCI23418

30. Maisonpierre PC, Suri C, Jones PF, Bartunkova S, Wiegand SJ, Radziejewski C et al (1997) Angiopoietin-2, a natural antagonist 
for Tie2 that disrupts in vivo angiogenesis. Science 277(5322):55-60. doi:10.1126/science.277.5322.55

31. Khurana R, Simons M, Martin JF, Zachary IC (2005) Role of angiogenesis in cardiovascular disease: a critical appraisal. Circulation 112(12):1813-1824. doi:10.1161/CIRCULATIONAHA. 105.535294

32. Lambert E, Dassé E, Haye B, Petitfrère E (2004) TIMPs as multifacial proteins. Crit Rev Oncol Hematol 49(3):187-198. doi: 10.1016/j.critrevonc.2003.09.008

33. Bloomston M, Shafii A, Zervos EE, Rosemurgy AS (2002) TIMP-1 overexpression in pancreatic cancer attenuates tumor growth, decreases implantation and metastasis, and inhibits angiogenesis. J Surg Res 102(1):39-44. doi:10.1006/jsre.2001. 6318

34. Seo DW, Li H, Guedez L, Wingfield PT, Diaz T, Salloum R et al (2003) TIMP-2 mediated inhibition of angiogenesis: an MMPindependent mechanism. Cell 114(2):171-180. doi:10.1016/ S0092-8674(03)00551-8

35. Lee S, Zheng M, Kim B, Rouse BT (2002) Role of matrix metalloproteinase-9 in angiogenesis caused by ocular infection with herpes simplex virus. J Clin Invest 110(8):1105-1111

36. Spinale FG (2002) Matrix metalloproteinases: regulation and dysregulation on the failing heart. Circ Res 90:520-530. doi: 10.1161/01.RES.0000013290.12884.A3

37. Creemers EEJM, Cleutjens JPM, Smits JFM et al (2001) Matrix metalloproteinase inhibition after myocardial infarction: a new approach to prevent heart failure? Circ Res 89:201-210. doi: 10.1161/hh1501.094396

38. Ikonomidis JS, Hendrick JW, Parkhurst AM, Herron AR, Escobar PG, Dowdy KB et al (2005) Accelerated LV remodeling after myocardial infarction in TIMP-1-deficient mice: effects of exogenous MMP inhibition. Am J Physiol Heart Circ Physiol 288(1):H149-H158. doi:10.1152/ajpheart.00370.2004

39. Taniyama Y, Morishita R, Nakagami H et al (2000) Potential contribution of a novel antifibrotic factor, hepatocyte growth factor, to prevention of myocardial fibrosis by angiotensin II blockade in cardiomyopathic hamsters. Circulation 102:246-252

40. Minatoguchi S, Takemura G, Chen XH, Wang N, Uno Y, Koda $M$ et al (2004) Acceleration of the healing process and myocardial regeneration may be important as a mechanism of improvement of cardiac function and remodeling by postinfarction granulocyte colony-stimulating factor treatment. Circulation 109(21):2572-2580. doi:10.1161/01.CIR.0000129770.93985.3E

41. Azuma J, Taniyama Y, Takeya Y, Iekushi K, Aoki M, Dosaka N et al (2006) Angiogenic and antifibrotic actions of hepatocyte growth factor improve cardiac dysfunction in porcine ischemic cardiomyopathy. Gene Ther 13(16):1206-1213. doi:10.1038/sj. gt. 3302740

42. Kollet O, Shirttail S, Chen YQ, Suriawinata J, Thung SN, Dabeva MD et al (2003) HGF, SDF-1, and MMP-9 are involved in stressinduced human CD34+ stem cell recruitment to the liver. J Clin Invest 112(2):160-169

43. Heissig B, Hattori K, Dias S, Friedrich M, Ferris B, Hackett NR et al (2002) Recruitment of stem and progenitor cells from the bone marrow niche requires MMP-9 mediated release of kitligand. Cell 109(5):625-637. doi:10.1016/S0092-8674(02)007 54-7

44. Segers VF, Tokunou T, Higgins LJ, MacGillivray C, Gannon J, Lee RT (2007) Local delivery of protease-resistant stromal cell derived factor- 1 for stem cell recruitment after myocardial infarction. Circulation 116(15):1683-1692. doi:10.1161/CIR CULATIONAHA.107.718718 